\title{
High dose pollen intralymphatic immunotherapy: two RDBPC trials question the benefit of dose increase
}

\author{
Lars Olaf Cardell $^{1}$, Laila Hellkvist ${ }^{1}$, Eric Hjalmarsson ${ }^{1}$, Dan Weinfeld ${ }^{2}$, Alsog Dahl ${ }^{3}$, \\ Agneta Karlsson ${ }^{1}$, Marit Westman ${ }^{4}$, Karin Lundkvist ${ }^{1}$, Ola Winquist ${ }^{5}$, Susanna Kumlien \\ Georén $^{1}$, and Ulla Westin ${ }^{6}$ \\ ${ }^{1}$ Karolinska Institutet Institutionen for klinisk vetenskap intervention och teknik \\ ${ }^{2}$ Sodra Alvsborgs sjukhus Boras \\ ${ }^{3}$ Goteborgs universitet Institutionen for Biologi och Miljovetenskap \\ ${ }^{4}$ Karolinska Institutet Institutionen for medicin Solna \\ ${ }^{5} \mathrm{ABC}$ labs Biomedicum Stockholm Sweden \\ ${ }^{6}$ Skanes universitetssjukhus Lund
}

June 30, 2021

\begin{abstract}
Background The same dosing schedule, 1000 SQ-U times three, with one-month intervals, have been evaluated in most trials of intralymphatic immunotherapy (ILIT) for the treatment of allergic rhinitis (AR). The present studies evaluated if a dose escalation in ILIT can enhance the clinical and immunological effects, without compromising safety. Methods Two randomized double-blind placebo-controlled trials of ILIT for grass pollen induced AR were performed. The first included 29 patients that had recently ended 3 years of SCIT and the second contained 39 not previously vaccinated patients. An up-dosage of 1000-3000-10 000 (5000 + 5000 with 30 minutes apart) SQ-U with one month in between was evaluated. Results Doses up to $10000 \mathrm{SQ}-\mathrm{U}$ was safe after recent SCIT. The combined symptom-medication scores (CSMS) were reduced by $31 \%$ and the grass specific IgG4 levels in blood were doubled. In ILIT de novo, the two first patients that received active treatment developed serious adverse reactions at $5000 \mathrm{SQ}-\mathrm{U}$. A modified up-dosing schedule; 1000-3000-3000 SQ-U appeared to be safe but failed to improve the CSMS. Flow cytometry analyses showed increased activation of lymph node derived dendritic but not T-cells. Quality of life and nasal provocation response did not improve in any study. Conclusion ILIT in high doses after SCIT appears to further reduce grass pollen induced seasonal symptoms and may be considered as an add-on treatment for patients that do not reach full symptom control after SCIT. Up-dosing schedules de novo with three monthly injections that exceeds 3000 SQ-U should be avoided.
\end{abstract}

\section{Hosted file}

Manuscript_v3.0_clean.docx available at https://authorea.com/users/391034/articles/528432high-dose-pollen-intralymphatic-immunotherapy-two-rdbpc-trials-question-the-benefit-ofdose-increase 

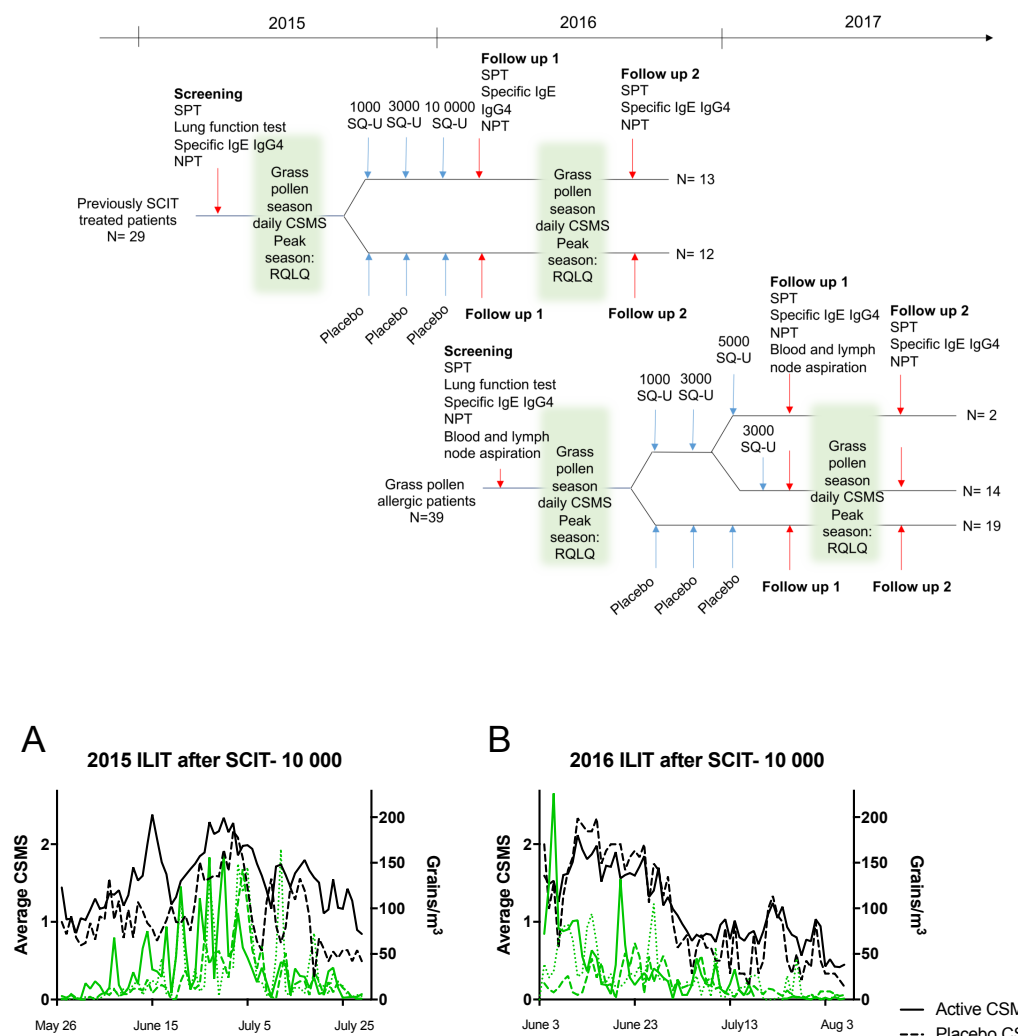

B 2016 ILIT after SCIT- 10000
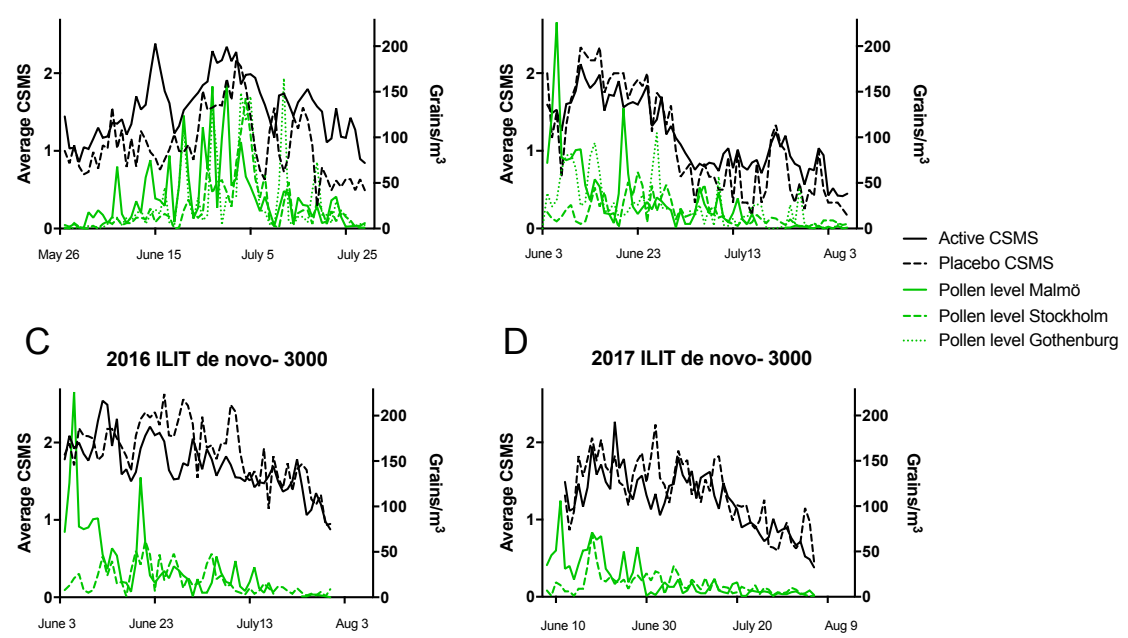
A. ILIT after SCIT- 10000

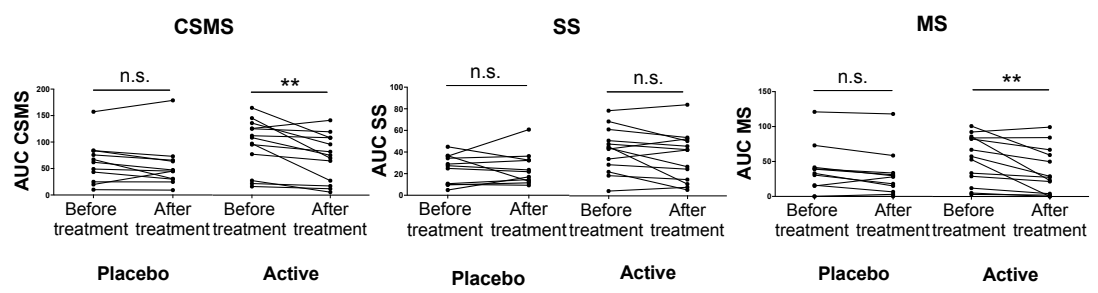

B. ILIT de novo- 3000

CSMS

ss

MS

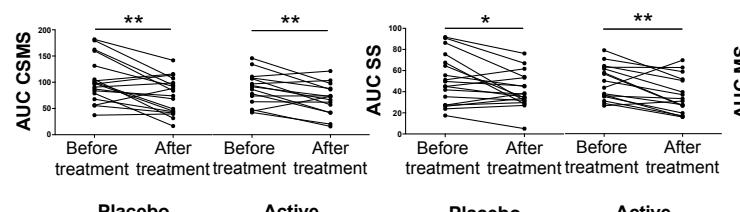

Placebo Active

Placebo Active

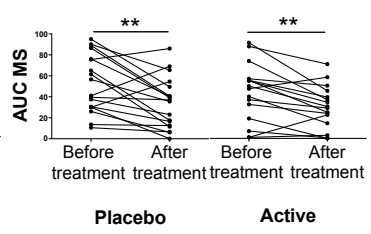

A

ILIT after SCIT- 10000

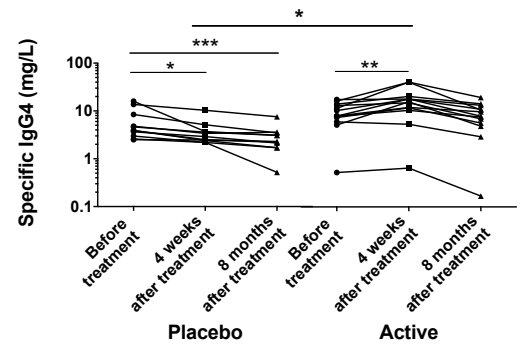

C

ILIT after SCIT- 10000

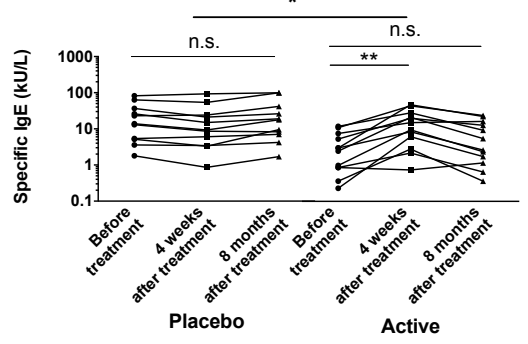

B

ILIT de novo- 3000

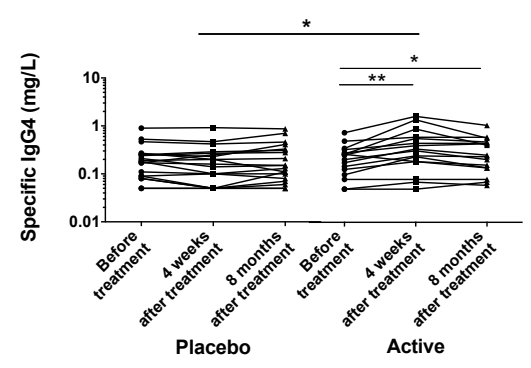

D

ILIT de novo- 3000

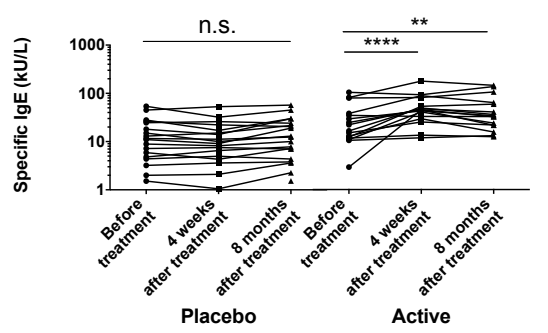



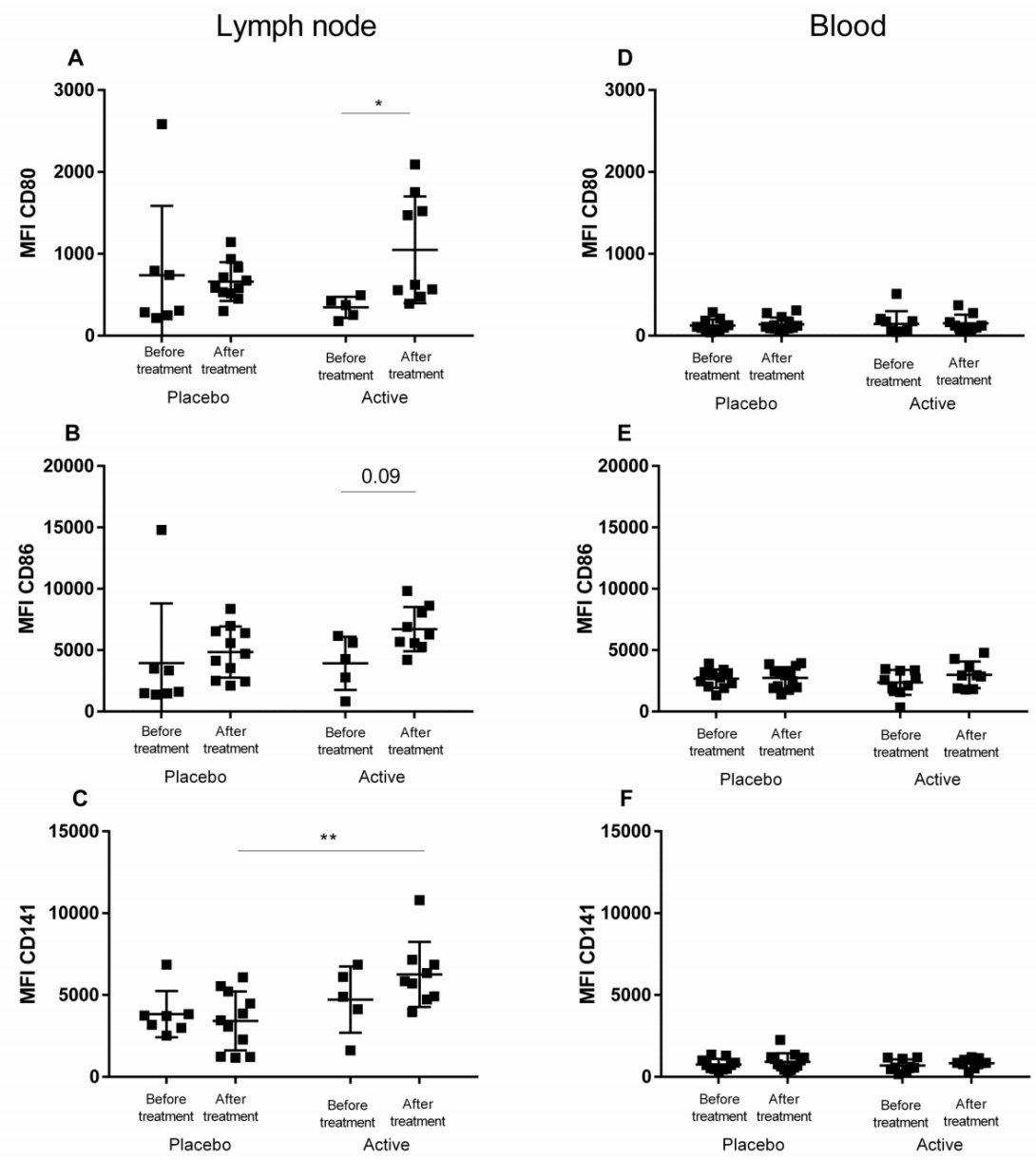